Review Article

\title{
Different Training Durations and Frequencies of Tai Chi for Bone Mineral Density Improvement: A Systematic Review and Meta-Analysis
}

\author{
Yi Zhou $\mathbb{D}^{1},{ }^{1}$ Zhi-Hui Zhao $\mathbb{D}^{2},{ }^{2}$ Xiao-Hong Fan $\mathbb{D}^{\mathbb{D}},{ }^{1}$ Wei-Hong $\mathrm{Li} \mathbb{D},{ }^{2}$ and Zhen Chen ${ }^{1}$ \\ ${ }^{1}$ Hospital of Chengdu University of Traditional Chinese Medicine, Chengdu, Sichuan 610072, China \\ ${ }^{2}$ Basic Medical College, Chengdu University of Traditional Chinese Medicine, Chengdu, Sichuan 611137, China
}

Correspondence should be addressed to Xiao-Hong Fan; fanxiaohong@cdutcm.edu.cn and Wei-Hong Li; lwh@cdutcm.edu.cn

Received 26 October 2020; Revised 2 February 2021; Accepted 25 February 2021; Published 16 March 2021

Academic Editor: Muhammad Nabeel Ghayur

Copyright (C) 2021 Yi Zhou et al. This is an open access article distributed under the Creative Commons Attribution License, which permits unrestricted use, distribution, and reproduction in any medium, provided the original work is properly cited.

\begin{abstract}
Objective. Tai Chi shows potential as a safe and cost-effective intervention to improve bone mineral density (BMD). However, the various effects caused by different training durations and frequencies have not been evaluated. This updated systematic review aims to explore the effectiveness of Tai Chi in attenuating bone mineral density loss based on different training durations and frequencies. Methods. We conducted an extensive database search in Cochrane Central Register of Controlled Trials, PubMed, EMBASE, Web of Science, Chinese Biomedical Literature Database, China Knowledge Resource Integrated Database, Wanfang Data, and China Science and Technology Journal Database on randomized controlled trials that examined Tai Chi for BMD improvement. Two reviewers independently performed data screening and extraction. Study quality was evaluated using the Cochrane Handbook for Systematic Reviews of Interventions. Results. A total of 23 randomized controlled trials involving 1582 patients were identified. The aggregated results have shown significant benefits in favor of Tai Chi on BMD improvement in the lumbar spine $(S M D=0.36,95 \%[0.13,0.59], P=0.002)$, femoral neck (SMD $=0.40,95 \%[0.16,0.63], P=0.0009)$, femoral trochanter $(\mathrm{SMD}=0.43,95 \% \mathrm{CI}[0.20,0.66], P=0.0002)$, and Ward's triangle (SMD $=0.31,95 \%[0.15,0.48], P=0.002)$. Such favorable benefits in Tai Chi can only be seen when compared with the nonexercise group, and Tai Chi showed no significant improvement in BMD change when compared with other exercises group. Subgroup analyses showed various effects of BMD improvement based on different training durations and frequencies of Tai Chi. Tai Chi is effective in attenuating BMD loss with an intervention frequency of $>4$ days/week in the lumbar spine, with an intervention frequency of $>4$ days/week or an intervention duration of $>10$ months in the femoral neck, and with an intervention duration of $>10$ months or a frequency of $\leq 4$ days/week in Ward's triangle. Conclusions. The results demonstrated that Tai Chi may have benefits in attenuating BMD loss. Different training durations and frequencies may result in variable effectiveness. Researchers should focus more on the training durations and frequencies of Tai Chi so that a more definitive claim can be made regarding the beneficial effects for BMD improvement.
\end{abstract}

\section{Introduction}

The decrease in bone mineral density (BMD) is closely related to age [1]. Osteoporosis caused by age-related bone loss puts a heavy burden on families and society $[2,3]$. Currently, there is no safe and effective radical cure to restore osteoporotic bones, making early prevention of osteoporosis particularly important $[4,5]$. The essential elements in preventing osteoporosis are achieving normal peak bone mass and attenuating age-related bone mass reduction [6].
In recent years, in addition to pharmaceutical treatments, the positive effect of exercise on bone density has attracted more and more attention $[7,8]$. Studies have shown that exercise can prevent and treat osteoporosis in the following ways: (1) it can stimulate osteoblasts and bone marrow stem cells to produce biological effects through mechanical stress $[9,10],(2)$ it can up-regulate the expression of key factors in signaling pathways including WNT, BMP, OPG/RANK/ RANKL $[11,12]$, and (3) it can regulate the endocrine system and increase the estrogen level in the body $[13,14]$. At 
present, the positive effect of exercise on osteoporosis has become a research hotspot.

Tai Chi is a mind-body, low-impact, weight-bearing exercise that is growing in popularity worldwide and shows potential as a safe and cost-effective intervention to improve $\mathrm{BMD}$. It is an enjoyable and gentle activity that involves the entire body with a high adherence [15]. A handful of studies have evaluated the effectiveness of Tai Chi on BMD [16-19], and more and more systematic reviews (SRs) in this field are emerging [20-23]. However, the retrieval time of the most recent SR is until 2017, and new randomized controlled trials (RCTs) have been published in the past two years. Besides, no SR focused on the BMD change in different body parts, as well as different BMD improvements caused by various intervention durations and frequencies of Tai Chi. Therefore, we conducted an updated SR to comprehensively and systematically evaluate the effects of Tai Chi on BMD change based on different training durations and frequencies and provided evidence-based recommendations to clinicians.

\section{Methods}

2.1. Data Sources and Search Strategies. The following databases were searched using a computer: Cochrane Central Register of Controlled Trials (CENTRAL), PubMed, EMBASE, Web of Science, Chinese Biomedical Literature Database (CBM), China Knowledge Resource Integrated Database (CNKI), Wanfang Data, and China Science and Technology Journal Database (VIP). The primary search terms used were "Taiji," "Bone mineral density," "Bone health," "Bone metabolism," "Osteoporosis." The retrieval time was from the establishment of the database to May 2020, and only studies published in English or Chinese were included. Relevant systematic reviews and the references to the included articles were also searched to supplement other potentially relevant literature.

\subsection{Criteria for Considering Studies for This Review.} Studies should meet the following inclusion criteria (PICO format): (1) Participants: individuals without serious complications. The age, gender, case source, nationality, disease duration, or race of subjects was not restricted. (2) Interventions: the experimental group was given Tai Chi Chuan, and the style, the intervention duration, and the intervention frequency were not restricted. Other Tai Chi exercises like Tai Chi push hands or Tai Chi ball were excluded. (3) Control: any type of control group, including usual care, conventional Western medicine, no exercise, and any kind of exercise, was acceptable. (4) Outcomes: the primary outcomes were dual-energy X-ray absorptiometry measures of BMD of the spine, the femoral neck, the femoral tuberosity, and Ward's triangle. (5) Study type: RCTs.

2.3. Literature Screening. Two investigators reviewed the titles and abstracts independently according to the preset inclusion criteria and excluded unrelated literature. Then full-text screening of the remained studies was carried out, and the two investigators identified the final included research independently according to the inclusion criteria. The results were cross-checked, and the investigators' differences were resolved by consensus with a third investigator.

2.4. Data Extraction. Two reviewers extracted the data while blinded to each other's review according to the prepiloted, standardized forms. The original author(s) was contacted in case of incomplete information provided in the article. The data extraction included the following aspects: (1) general information: first author, publication year, literature topics; (2) research characteristics: baseline comparability, sample size, sex ratio, country, intervention measures, treatment course, follow-up; (3) outcome indicators; and (4) relevant factors for evaluating the risk of bias. A third reviewer was consulted if there was disagreement during cross-correction.

2.5. Assessment of Risk of Bias in Included Studies. Two reviewers independently assessed the risk of bias in accordance with the assessment tool suggested in the Cochrane Handbook for Systematic Reviews of Interventions [24] and then conducted cross-checking. The following aspects were included: random sequence generation (selection bias); allocation concealment (selection bias); blinding of participants and personnel (performance bias); blinding of outcome assessment (detection bias); incomplete outcome data (attrition bias); selective reporting (reporting bias); and other sources of bias [24]. Any disagreement during this procedure was resolved by consensus with a third investigator. RevMan 5.3 provided by the Cochrane Collaboration was used to created plots demonstrating the risks of bias.

2.6. Statistical Analysis. Revman 5.3 was also used for statistical analysis. All outcomes were continuous variables and were calculated as standard mean difference (SMD) and 95\% confidence interval (CI). We extracted the mean and standard deviation of the change from baseline and transformed it into a standard format to make sure that it was implemented successfully in our analysis. The chi-square test and $I^{2}$ statistic were used to check the heterogeneity of the results. $P \geq 0.1$ or $I^{2}<50 \%$ was considered to indicate low heterogeneity, and a fixed-effects model was established for statistical analysis; otherwise, subgroup analyses according to control type, intervention duration, and intervention frequency were performed, as well as sensitivity analyses if necessary. Publication bias was estimated with a funnel plot.

\section{Results}

3.1. Literature Screening. Six hundred thirty-one original studies were collected by database searching, and $205 \mathrm{du}-$ plicate studies were excluded. After screening the titles and abstracts of the remaining literature, 367 articles were excluded, including non-RCTs and irrelevant publications. Then the full texts were read, and another 43 studies were excluded due to their nonconforming interventions, inadequate control groups, and inaccurate evaluation indicators. 
At last, 16 studies, 23 RCTs were included [16-18, 25-37]. The specific screening process and results are displayed in Figure 1.

3.2. Characteristics of Included Studies. A total of 16 studies [16-18, 25-37], 23 RCTs, involving 1582 patients were included (Table 1). The settings of the included trials were diverse and included China, South Korea [17], and the United States of America [16]. Among these 23 trials, ten trials $[16,17,25-29,34]$ had an intervention duration of $\leq 10$ months, and 13 trials had $>10$ months. The intervention frequency in each RCT was also different, 10 $[27,28,33-35,37,38]$ of which were $\leq 4$ days/week and 13 were $>4$ days/week. The interventions in the control groups included no exercise [16-18, 25-28, 31-36] and other exercises such as rapid walk [30], dance [30], rope skipping [29], and resistance exercise [37]. The outcomes included were as follows: the BMD change in the spine was used in 22 trials $[16,18,25-37]$, the BMD change in the femoral neck was used in 15 trials $[16-18,25-28,30-33,35,36]$, the BMD change in the femoral tuberosity was used in 13 trials $[18,25,30-33,35,36]$, and the BMD change in Ward's triangle was used in 12 trials $[27,30-33,35,36]$.

3.3. Assess of Risk of Bias. The risk of bias assessment of all included studies is shown in Figures 2 and 3. Four trials reported the method of randomization in terms of a computer-generated random sequence [16, 17, 37]; 6 trials used a random number table [30,32, 35, 36]; 1 trial applied the method of drawing lots [27]; the remaining trials lacked descriptions of particular random sequence generation method. Four trials used sealed opaque envelopes to perform the allocation concealment $[16,26,37]$, while the remaining trails failed to provide sufficient details about allocation concealment. Due to the apparent difference, whether to use Tai Chi or not, between the two groups, a blind method could not be used in the participants or administrators in these studies. Four trials were shown to blind its outcome assessment [16, 17, 37]. Five trials reported a high but nonrandom drop-out rate $[17,27,30]$. All studies reported all outcomes listed in their methods section. The data necessary for judging the risk of other biases in all trials were insufficient.

\subsection{Meta-Analysis of Measured Outcomes}

3.4.1. BMD Change in the Lumbar spine (L2-L4). A total of 22 RCTs with 1367 patients were included [16, 18, 25-37], 677 of which underwent a Tai Chi intervention. A random effect model was used to perform the meta-analysis on account of the high heterogeneity $\left(I^{2}=72 \%, P<0.00001\right)$. The pooled result indicated a favorable effect of Tai Chi on $\mathrm{BMD}$ change in the spine compared to the control group $(\mathrm{SMD}=0.36,95 \%[0.13,0.59], P=0.002)$ (Figure 4).

Subgroup Analyses Based on Control Types, Intervention Durations, and Intervention Frequencies. First, subgroup analysis according to control type (nonexercise and other exercises) was performed. Four trials $[29,30,37]$ reported a control type of other exercises, while 18 trials [16, 18, 25-37] reported no exercise. The pooled result showed that Tai Chi did not significantly improve BMD of the lumbar spine $(\mathrm{SMD}=-0.18,95 \%[-0.51,0.15], P=0.29)$ compared to other exercises group with low heterogeneity $\left(I^{2}=0 \%\right.$, $P=0.43$ ), and that Tai Chi was superior to nonexercise group in improving BMD of the lumbar spine $(\mathrm{SMD}=0.44$, $95 \%[0.19,0.68], P=0.0005)$ with high heterogeneity $\left(I^{2}=73 \%, P<0.00001\right)$.

Then, we conducted subgroup analyses according to intervention durations ( $>10$ months and $\leq 10$ months) and intervention frequencies ( $>4$ days/week and $\leq 4$ days/week) in the nonexercise group (Table 2). The pooled results showed that Tai Chi significantly improved BMD of the lumbar spine with an intervention frequency of $>4$ days/ week $\quad(\mathrm{SMD}=0.67, \quad 95 \% \quad[0.25, \quad 1.09], \quad P=0.002)$ $[18,25,26,28,30-33,36]$ rather than of $\leq 4$ days/week $(\mathrm{SMD}=0.16, \quad 95 \% \quad[-0.02, \quad 0.35], \quad P=0.09)$ $[16,27,29,33-35,37]$, and that Taiji was superior to no exercise group in improving BMD of the lumbar spine with intervention durations of either $>10$ months $(\mathrm{SMD}=0.50$, $95 \%[0.13,0.86], P=0.008)[18,30-33,35-37]$ or $\leq 10$ months $(\mathrm{SMD}=0.38,95 \%[0.04,0.71], P=0.03)[25-29,34]$.

\subsubsection{BMD Change in the Femoral Neck. Fifteen RCTs were} included with a total of 1008 patients $[16,18,25-27,30-33,35,36]$. The pooled result showed a significant difference between the two groups in BMD change in the femoral neck $(\mathrm{SMD}=0.40,95 \%[0.16,0.63]$, $P=0.0009)$, with high heterogeneity $\left(I^{2}=66 \%, P=0.0001\right)$ (Figure 5).

Subgroup Analyses Based on Control Types, Intervention Durations, and Intervention Frequencies. We firstly conducted subgroup analysis according to control type (nonexercise and other exercises). For the comparison between the Tai Chi and the other exercises group, the pooled data from 2 trials [30] showed that no significant difference was found in BMD improvement in the femoral neck (SMD $=0.12,95 \%[-0.41,0.64], P=0.67)$ between the two groups with low heterogeneity $\left(I^{2}=0 \%, P=0.97\right)$. For the comparison between the Tai Chi and the nonexercise group, the combined result of 18 RCTs [16, 18, 25-27, 30-33, 35, 36] showed that Tai Chi could significantly improve BMD of the femoral neck (SMD $=0.43,95 \%[0.17,0.68], P=0.001)$ with high heterogeneity $\left(I^{2}=70 \%, P<0.0001\right)$.

Subgroup analyses according to intervention durations ( $>10$ months and $\leq 10$ months) and intervention frequencies ( $>4$ days/week and $\leq 4$ days/week) were secondly carried out in the nonexercise group (Table 3 ). The pooled results showed that Tai Chi had a better effect on BMD improvement with an intervention frequency of $>4$ days/week $(\mathrm{SMD}=0.53, \quad 95 \% \quad[0.15, \quad 0.91], \quad P=0.006)$ $[18,25,26,30-32,34,36]$ and an intervention duration of $>10$ months $(\mathrm{SMD}=0.51,95 \%[0.12,0.91], P=0.01)$ $[26,30,32,33,35,36]$. No significant difference between the 


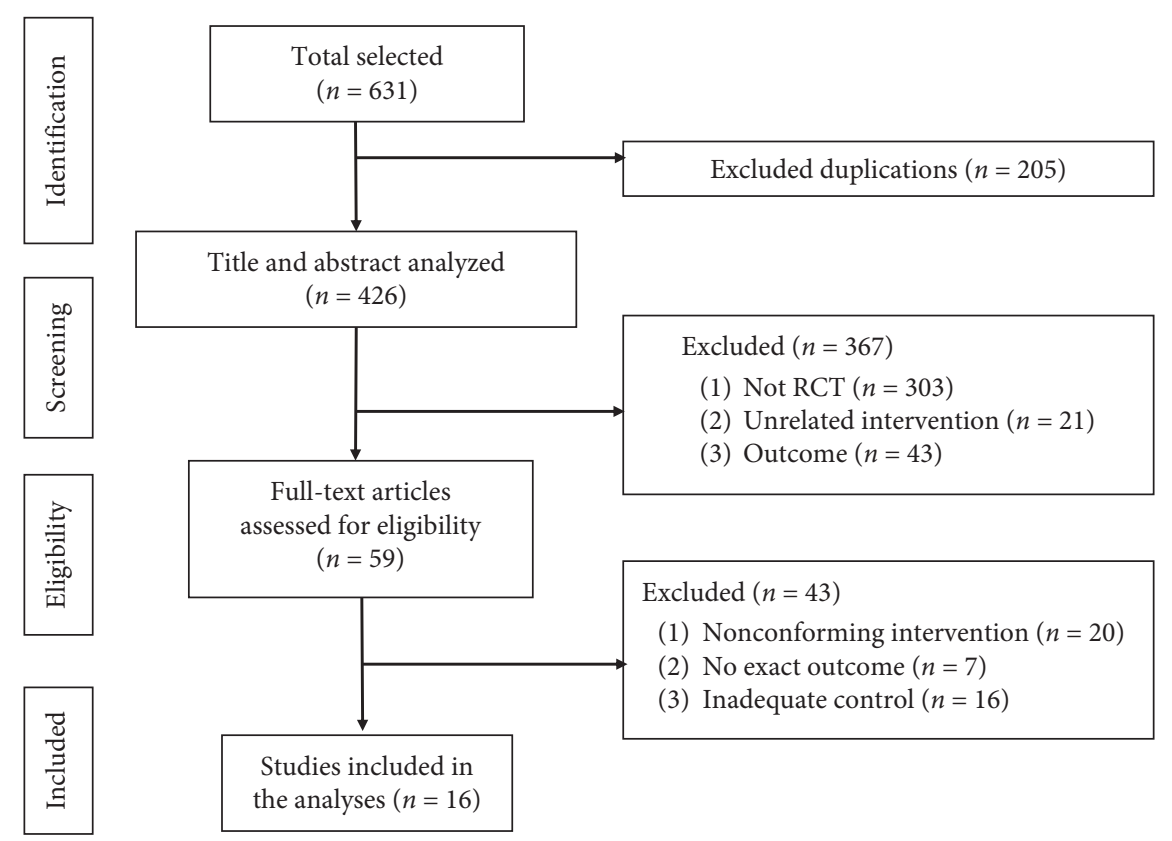

Figure 1: Flow chart of selection process.

TABLE 1: Characteristics of included studies.

\begin{tabular}{|c|c|c|c|c|c|c|c|c|c|}
\hline \multirow{2}{*}{$\begin{array}{l}\text { Author } \\
\text { year }\end{array}$} & \multirow[b]{2}{*}{ Location } & \multirow[b]{2}{*}{ Participants } & \multirow[b]{2}{*}{$\begin{array}{l}\text { No. } \\
(\mathrm{T} / \mathrm{C})\end{array}$} & \multicolumn{3}{|c|}{ Tai Chai group } & \multirow{2}{*}{$\begin{array}{c}\text { Control } \\
\text { group }\end{array}$} & \multirow{2}{*}{$\begin{array}{l}\text { Training } \\
\text { duration } \\
\text { (months) }\end{array}$} & \multirow[b]{2}{*}{ Outcome } \\
\hline & & & & $\begin{array}{l}\text { Style or } \\
\text { form }\end{array}$ & Daily time & $\begin{array}{c}\text { Frequency } \\
\text { (days/week) }\end{array}$ & & & \\
\hline $\mathrm{Xu}, 2017$ & China & Menopausal women & $43 / 43$ & 24 form & $\geq 40 \mathrm{~min}$ & 6 & Nonexercise & 12 & (1) (2) (3) (4) \\
\hline $\begin{array}{l}\mathrm{Li}, 2017 \\
(\mathrm{~L})^{*}\end{array}$ & China & Women aged 60 to 70 & $36 / 12$ & 24 form & $60 \mathrm{~min}$ & 1 & Nonexercise & 12 & (1) (2) (3) (4) \\
\hline $\begin{array}{l}\mathrm{Li}, 2017 \\
(\mathrm{M})^{*}\end{array}$ & China & Women aged 60 to 70 & $37 / 12$ & 24 form & $60 \mathrm{~min}$ & 3 & Nonexercise & 12 & (1) (2) (3) (4) \\
\hline $\begin{array}{l}\mathrm{Li}, 2017 \\
(\mathrm{M})^{*}\end{array}$ & China & Women aged 60 to 70 & $38 / 12$ & 24 form & $60 \mathrm{~min}$ & 6 & Nonexercise & 12 & (1) (2) (3) (4) \\
\hline $\begin{array}{l}\text { Song, } \\
2018^{\#}\end{array}$ & China & Women aged 60 to 70 & $9 / 29$ & 24 form & $70 \mathrm{~min}$ & 5 & $\begin{array}{c}\text { Rapid } \\
\text { working }\end{array}$ & 12 & (1) (2) (3) (4) \\
\hline $\begin{array}{l}\text { Song, } \\
2018^{\#}\end{array}$ & China & Women aged 60 to 70 & $9 / 32$ & 24 form & $70 \mathrm{~min}$ & 5 & Dancing & 12 & (1) (2) (3) (4) \\
\hline $\begin{array}{l}\text { Song, } \\
2018^{\#}\end{array}$ & China & Women aged 60 to 70 & $9 / 31$ & 24 form & $70 \mathrm{~min}$ & 5 & Nonexercise & 12 & (1) (2) (3) (4) \\
\hline $\begin{array}{l}\text { Song, } \\
2008\end{array}$ & China & $\begin{array}{c}\text { Patients with primary } \\
\text { osteoporosis }\end{array}$ & $20 / 20$ & 24 form & $60 \mathrm{~min}$ & 6 & Nonexercise & 12 & (1) (2) \\
\hline $\begin{array}{l}\text { Mao, } \\
2009^{\S}\end{array}$ & China & Retired women & $20 / 20$ & $\begin{array}{c}\text { Not } \\
\text { reported }\end{array}$ & $30 \mathrm{~min}$ & 3 & Nonexercise & 5 & (1) \\
\hline $\begin{array}{l}\text { Mao, } \\
200^{\S}\end{array}$ & China & Retired women & $20 / 20$ & $\begin{array}{c}\text { Not } \\
\text { reported }\end{array}$ & $30 \mathrm{~min}$ & 3 & $\begin{array}{l}\text { Western } \\
\text { medicine }\end{array}$ & 5 & (1) \\
\hline $\begin{array}{l}\text { Zhou, } \\
2014\end{array}$ & China & $\begin{array}{c}\text { Patient with } \\
\text { hyperlipidemia }\end{array}$ & $20 / 20$ & $\begin{array}{c}\text { Not } \\
\text { reported }\end{array}$ & $90 \mathrm{~min}$ & 4 & Nonexercise & 6 & (1) (2) (3) (4) \\
\hline Ye, 2016 & China & $\begin{array}{l}\text { Middle-aged and } \\
\text { elderly women }\end{array}$ & $25 / 25$ & $\begin{array}{c}\text { Not } \\
\text { reported }\end{array}$ & $30-60 \mathrm{~min}$ & 3 & Nonexercise & 6 & (1) (2) (4) \\
\hline $\begin{array}{l}\text { Shan, } \\
2015\end{array}$ & China & Menopausal women & $60 / 60$ & 24 form & $60 \mathrm{~min}$ & 7 & Nonexercise & 6 & (2) \\
\hline Ma, 2006 & China & Male & $32 / 35$ & 24 form & $60 \mathrm{~min}$ & 7 & Nonexercise & 12 & (1) (2) (3) (4) \\
\hline Bao, 2016 & China & $\begin{array}{c}\text { Patients with type } 2 \\
\text { diabetes }\end{array}$ & $58 / 49$ & $\begin{array}{c}\text { Not } \\
\text { reported }\end{array}$ & 4 hours & 7 & Nonexercise & 6 & (1) (3) (4) \\
\hline $\begin{array}{l}\text { Zhao, } \\
2020\end{array}$ & China & Menopausal women & $36 / 38$ & 24 form & $60 \mathrm{~min}$ & 3 & Nonexercise & 12 & (1) (2) (3) (4) \\
\hline $\begin{array}{l}\text { Chan, } \\
2004\end{array}$ & China & Menopausal women & $67 / 65$ & $\begin{array}{l}\text { Yang- } \\
\text { style }\end{array}$ & $45 \mathrm{~min}$ & 5 & Nonexercise & 12 & (1) (3) \\
\hline
\end{tabular}


TABLE 1: Continued.

\begin{tabular}{|c|c|c|c|c|c|c|c|c|c|}
\hline \multirow[b]{2}{*}{$\begin{array}{l}\text { Author } \\
\text { year }\end{array}$} & \multirow[b]{2}{*}{ Location } & \multirow[b]{2}{*}{ Participants } & \multirow[b]{2}{*}{$\begin{array}{l}\text { No. } \\
(\mathrm{T} / \mathrm{C})\end{array}$} & \multicolumn{3}{|c|}{ Tai Chai group } & \multirow[b]{2}{*}{$\begin{array}{l}\text { Control } \\
\text { group }\end{array}$} & \multirow{2}{*}{$\begin{array}{l}\text { Training } \\
\text { duration } \\
\text { (months) }\end{array}$} & \multirow[b]{2}{*}{ Outcome } \\
\hline & & & & $\begin{array}{l}\text { Style or } \\
\text { form }\end{array}$ & Daily time & $\begin{array}{l}\text { Frequency } \\
\text { (days/week) }\end{array}$ & & & \\
\hline $\begin{array}{l}\text { Woo, } \\
2007\end{array}$ & China & $\begin{array}{l}\text { Participants aged } 65 \\
\text { to } 74\end{array}$ & $58 / 29$ & $\begin{array}{l}\text { Yang- } \\
\text { style }\end{array}$ & $\begin{array}{l}\text { Not } \\
\text { reported }\end{array}$ & 3 & $\begin{array}{l}\text { Resistance } \\
\text { exercise }\end{array}$ & 12 & (1) \\
\hline $\begin{array}{l}\text { Woo, } \\
2007\end{array}$ & $\begin{array}{l}\text { South } \\
\text { Korea }\end{array}$ & $\begin{array}{c}\text { Participants aged } 65 \\
\text { to } 74\end{array}$ & $58 / 29$ & $\begin{array}{l}\text { Yang- } \\
\text { style }\end{array}$ & $\begin{array}{l}\text { Not } \\
\text { reported }\end{array}$ & 3 & Nonexercise & 12 & (1) \\
\hline $\begin{array}{l}\text { Song, } \\
2010\end{array}$ & $\begin{array}{l}\text { South } \\
\text { Korea }\end{array}$ & $\begin{array}{l}\text { Women with } \\
\text { osteoarthritis }\end{array}$ & $41 / 41$ & Sun-style & $45-60 \min$ & 7 & Nonexercise & 6 & (2) (3) (4) \\
\hline $\begin{array}{l}\text { Wayne, } \\
2012\end{array}$ & USA & $\begin{array}{c}\text { Post-menopausal } \\
\text { osteoarthritis women }\end{array}$ & $43 / 43$ & $\begin{array}{l}\text { Not } \\
\text { reported }\end{array}$ & $30-60 \mathrm{~min}$ & 4 & Nonexercise & 9 & (1) \\
\hline $\begin{array}{l}\text { Zhou, } \\
2004^{£}\end{array}$ & China & Menopausal women & $3 / 12$ & $\begin{array}{l}24 \text { or } 42 \\
\text { form }\end{array}$ & $45-60 \mathrm{~min}$ & 7 & Nonexercise & 10 & (1) \\
\hline $\begin{array}{l}\text { Zhou, } \\
2004^{£}\end{array}$ & China & Menopausal women & $3 / 12$ & $\begin{array}{l}24 \text { or } 42 \\
\text { form }\end{array}$ & $45-60 \mathrm{~min}$ & 7 & Rope skiing & 10 & (1) \\
\hline
\end{tabular}

(1) BMD in the lumbar spine; (2) BMD in the femoral neck; (3) BMD in the femoral trochanter; (4) BMD in Ward's triangle; ${ }^{*}$ RCTs with the same superscript belong to one study. T/C: Tai Chi/Control.

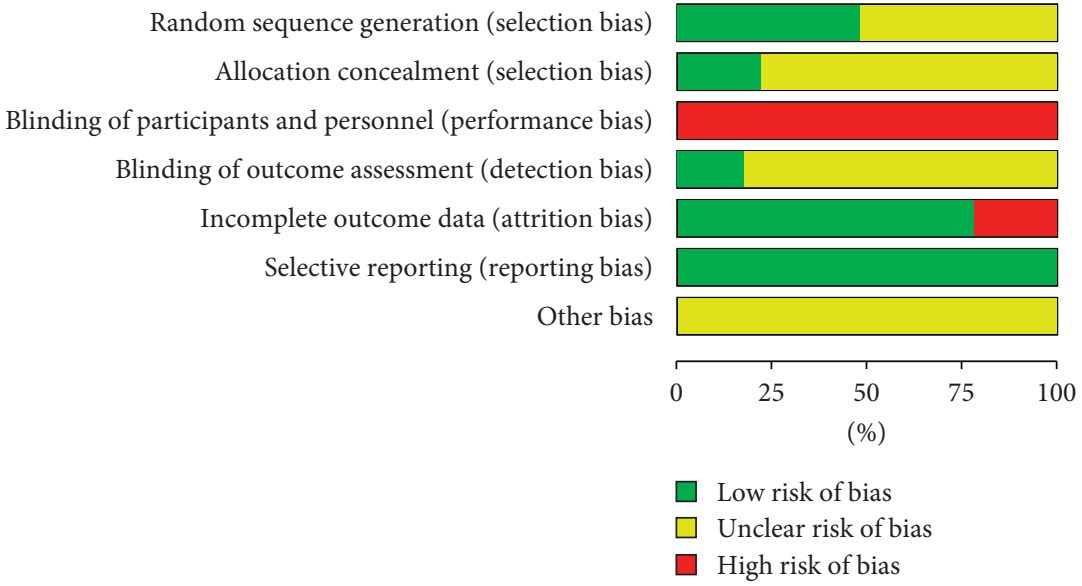

FIgURE 2: Risk of bias graph.

Tai Chi and the no exercise group in BMD improvement of the femoral neck was found in an intervention duration of $\leq 10$ months $(\mathrm{SMD}=0.31,95 \%[-0.01,0.63], P=0.06)$ $[16,18,25,27,31]$ and an intervention frequency of $\leq 4$ days/ week $\quad(\mathrm{SMD}=0.24, \quad 95 \% \quad[0.00, \quad 0.48], \quad P=0.05)$ $[16,27,33,35]$.

3.4.3. BMD Changes in the Femoral Trochanter. Thirteen trials involving 813 participants examined changes in the femoral trochanter $[18,25,28,30-33,35,36]$. The combined result showed a significant difference between the two groups (SMD $=0.43,95 \% \mathrm{CI}[0.20,0.66], P=0.0002)$ with high heterogeneity $\left(I^{2}=56 \%, P=0.007\right)$ (Figure 6).

Subgroup Analyses Based on Control Types, Intervention Durations, and Intervention Frequencies. Subgroup analysis according to control type (nonexercise and other exercises) was first conducted. Pooled BMD changes in the femoral trochanter improved significantly in the Tai Chi group compared to the nonexercise group $(\mathrm{SMD}=0.49,95 \%[0.23$, $0.74], \quad P=0.0002)$ with high heterogeneity $\left(I^{2}=60 \%\right.$, $P=0.005) \quad[18,25,28,30-33,35,36]$. No significant difference between the Tai Chi and the other exercises group was found $(\mathrm{SMD}=0.04,95 \%[-0.49,0.56], P=0.89)$ with low heterogeneity $\left(I^{2}=70 \%, P<0.0001\right)$ [30].

We subsequently conducted subgroup analyses according to intervention durations ( $>10$ months and $\leq 10$ months) and intervention frequencies ( $>4$ days/week and $\leq 4$ days/week) in the nonexercise group (Table 4 ). The combined results showed that Tai Chi was superior to the nonexercise group with either an intervention duration of $\leq 10$ months $(\mathrm{SMD}=0.68,95 \%[0.11,1.26], P=0.02)$ $[25,28,31]$ or a duration of $>10$ months $(\mathrm{SMD}=0.41,95 \%$ $[0.15,0.67], P=0.002)[18,30,32,33,35,36]$, as well as with either an intervention frequency of $\leq 4$ days/week $(\mathrm{SMD}=0.52,95 \%[0.17,0.87], P=0.003)[28,33,35]$ or a frequency of $>4$ days/week $(\mathrm{SMD}=0.46,95 \%[0.11,0.81]$, $P=0.009)[18,25,30-33,36]$.

3.4.4. BMD Changes in Ward's Triangle. Twelve RCTs reported BMD changes in Ward's triangle, with 637 individuals $[27,28,30-33,35,36]$. The 12 trials' heterogeneity was relatively low $\left(I^{2}=32 \%, P=0.14\right)$, so we chose to 


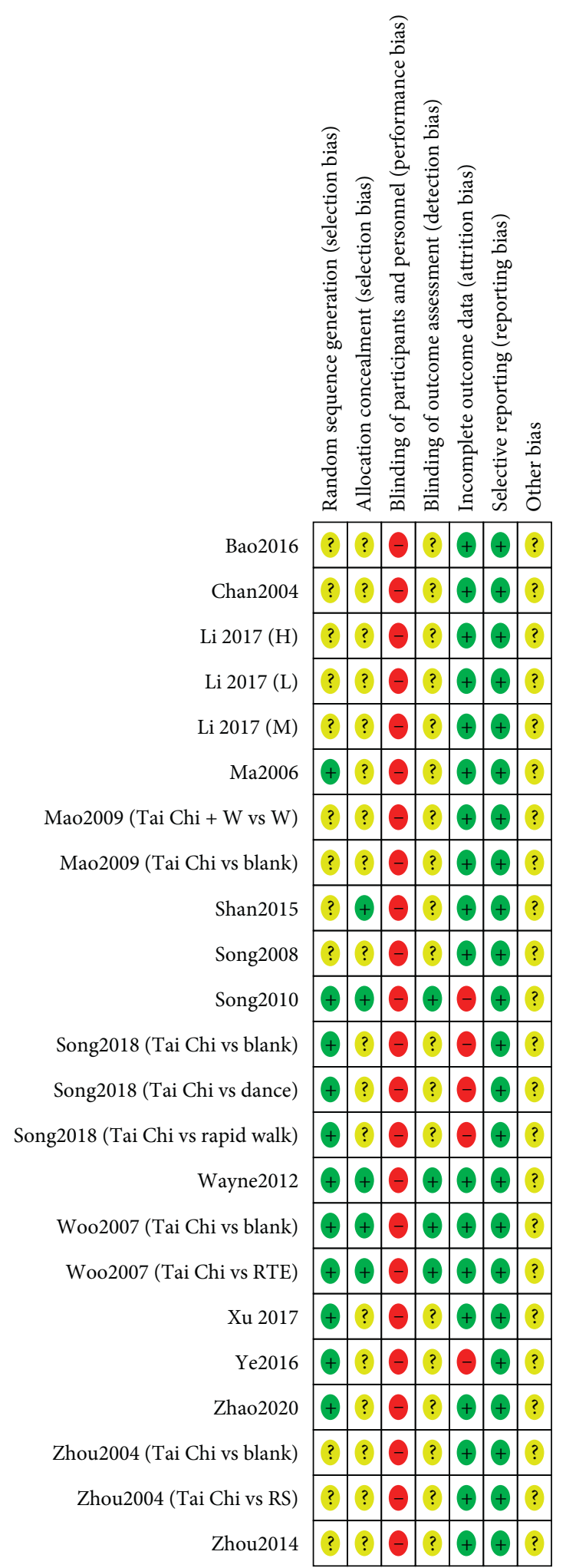

Figure 3: Risk of bias summary.

conduct a quantitative synthesis using a fixed effect model. The combined result was statistically significant $(\mathrm{SMD}=0.31,95 \%[0.15,0.48], P=0.002)$ compared to the control group, showing favorable effects of Taiji on BMD changes in Ward's triangle (Figure 7).
Subgroup Analyses Based on Control Types, Intervention Durations, and Intervention Frequencies. Firstly, we carried out a subgroup analysis according to the control type (nonexercise and other exercises). The pooled result of 10 studies comparing the Tai Chi and the nonexercise group 


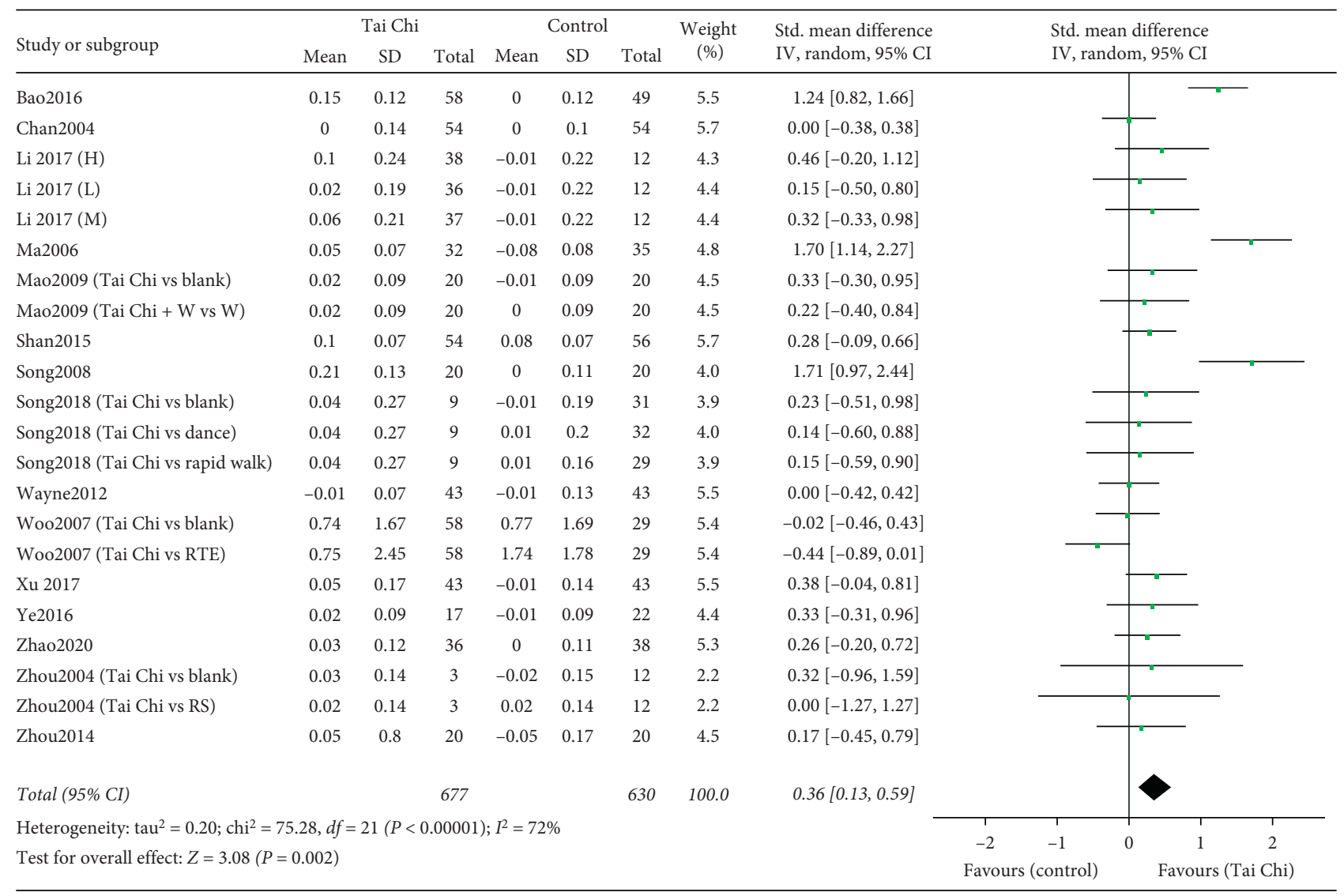

FIgURE 4: Forest plot of the comparison between the Tai Chi and the control group for the outcome BMD change in the lumbar spine (L2-L4).

TABLE 2: Subgroup analyses between the Tai Chi and the nonexercise group for the outcome BMD change in the lumbar spine (L2-L4) according to intervention durations and frequencies.

\begin{tabular}{|c|c|c|c|c|}
\hline Subgroup & $n$ & SMD, 95\% CI & $P$ & Heterogeneity \\
\hline \multicolumn{5}{|c|}{ Intervention duration } \\
\hline$\leq 10$ months & 8 & $\begin{array}{c}0.38,95 \%[0.04 \\
0.71]\end{array}$ & 0.03 & $I^{2}=66 \%, P=0.005$ \\
\hline$>10$ months & 10 & $\begin{array}{c}0.50,95 \%[0.13 \\
0.86]\end{array}$ & 0.008 & $\begin{array}{c}I^{2}=78 \% \\
P<0.00001\end{array}$ \\
\hline \multicolumn{5}{|c|}{ Intervention frequencies } \\
\hline $\begin{array}{l}\leq 4 \text { days/ } \\
\text { week }\end{array}$ & 9 & $\begin{array}{c}0.16,95 \%[-0.02 \\
0.35]\end{array}$ & 0.09 & $I^{2}=0 \%, P=0.97$ \\
\hline$>$ days/week & 9 & $\begin{array}{l}0.67,95 \%[0.25 \\
1.09]\end{array}$ & 0.002 & $\begin{array}{c}I^{2}=84 \% \\
P<0.00001\end{array}$ \\
\hline
\end{tabular}

showed a significant difference $(\mathrm{SMD}=0.36,95 \%[0.13$, $0.58], P=0.002)$ with low heterogeneity $\left(I^{2}=37 \%, P=0.12\right)$ $[27,28,30-33,35,36]$, while no significant difference was found between the Tai Chi and other exercises group $(\mathrm{SMD}=-0.04,95 \%[-0.56,0.49], P=0.89)$ with low heterogeneity $\left(I^{2}=0 \%, P=0.89\right)$ [30].

Secondly, subgroup analyses according to intervention durations ( $>10$ months and $\leq 10$ months) and intervention frequencies ( $>4$ days/week and $\leq 4$ days/week) were carried out in the nonexercise group (Table 5). The combined results showed that Tai Chi was superior to the nonexercise group with an intervention duration of $>10$ months $(\mathrm{SMD}=0.38$, $95 \%[0.03,0.73], P=0.03)[32,33,35,36]$ rather than of $\leq 10$ months $(\mathrm{SMD}=0.31,95 \%[0.00,0.61], P=0.05)[27,28,30]$, as well as with an intervention frequencies of $\leq 4$ days/week $(\mathrm{SMD}=0.37,95 \%[0.11,0.64], P=0.006)[27,28,33,35]$ rather than of $>4$ days/week $(\mathrm{SMD}=0.35,95 \%[-0.09,0.79]$, $P=0.12)[30-33,36]$.

3.4.5. Publication Bias. The funnel plot was drawn based on RCTs that included the outcome of BMD change in the lumbar spine (L2-L4). The funnel plot was obviously asymmetrical, suggesting that publication bias might exist (Figure 8). Four RCTs, which were significantly a skewed in the graph, showed no difference in methodology and other aspects [25, 31, 36, 37].

3.4.6. Safety Monitoring. Three RCTs reported that there were no serious adverse events $[16,35,36]$, while the remaining trials did not mention adverse events.

\section{Discussion}

Currently, there are several meta-analyses published on the same topic, as presented in Table 6. The highlights of our work are as follows: (1) firstly, our analyses included new RCTs that were published in the past two years. Since the 


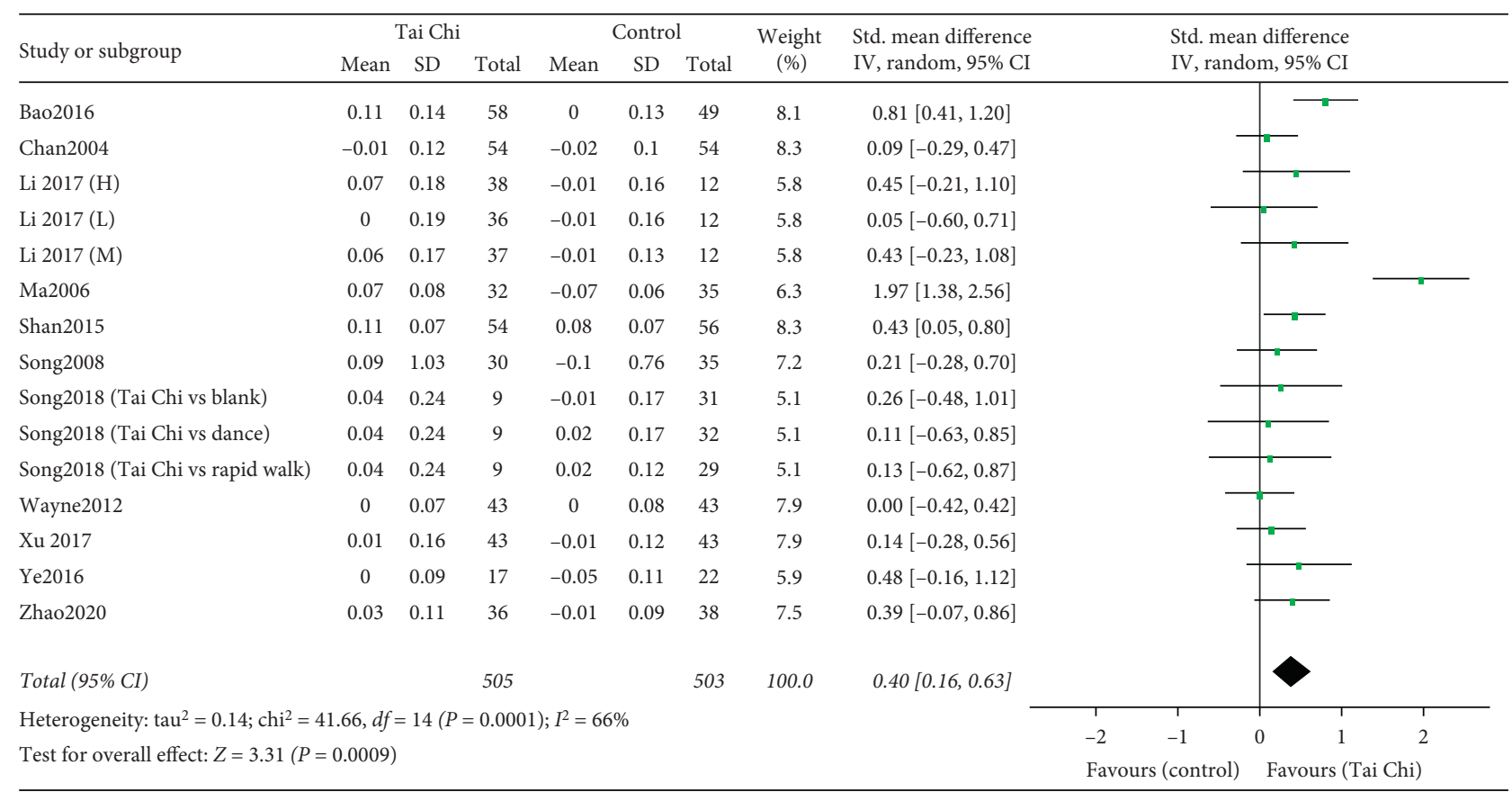

FIGURE 5: Forest plot of the comparison between the Tai Chi and the control group for the outcome BMD change in the femoral neck.

TABle 3: Subgroup analyses between the Tai Chi and the nonexercise group for the outcome BMD change in the femoral neck according to intervention durations and frequencies.

\begin{tabular}{lcccc}
\hline Subgroup & $n$ & SMD, 95\% CI & $P$ & Heterogeneity \\
\hline Intervention duration & & & 0.06 & $I^{2}=59 \%, P=0.04$ \\
$\quad 510$ months & 5 & $0.31,95 \%[-0.01,0.63]$ & 0.01 & $I^{2}=76 \%, P=0.0001$ \\
$\quad 8$ & $0.51,95 \%[0.12,0.91]$ & & \\
$\quad$ Intervention frequencies & & & 0.05 & $I^{2}=0 \%, P=0.59$ \\
$\quad \leq 4$ days/week & 5 & $0.24,95 \%[-0.00,0.48]$ & 0.006 & $I^{2}=80 \%, P<0.00001$ \\
$\quad>$ days/week & 8 & $0.53,95 \%[0.15,0.91]$ &
\end{tabular}

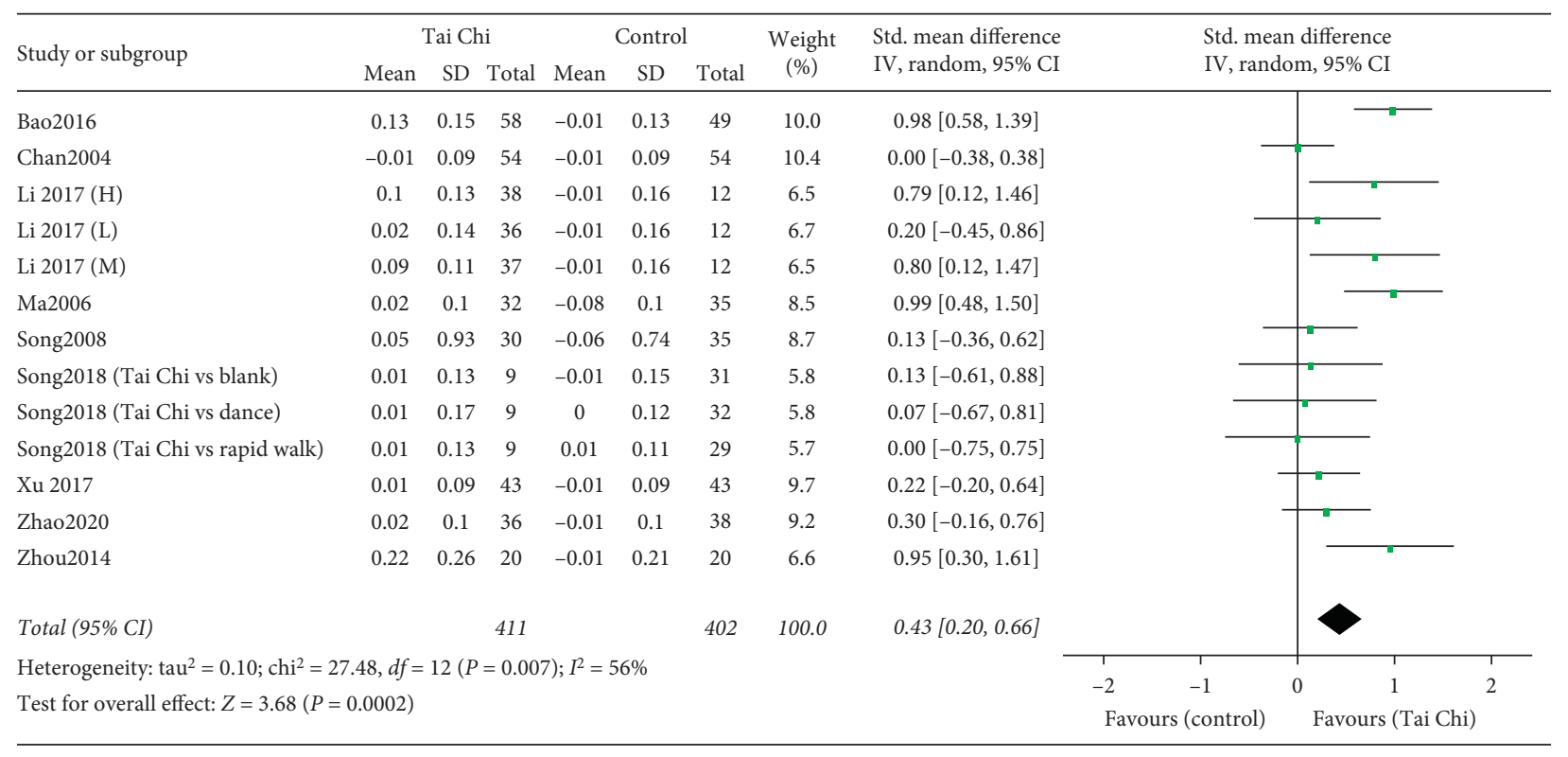

Figure 6: Forest plot of the comparison between the Tai Chi and the control group for the outcome BMD change in the femoral trochanter. 
TABLE 4: Subgroup analyses between the Tai Chi and the nonexercise group for the outcome BMD change in the femoral trochanter according to intervention durations and frequencies.

\begin{tabular}{lcccc}
\hline Subgroup & $n$ & SMD, 95\%CI & $P$ & Heterogeneity \\
\hline Intervention duration & & & & \\
$\quad \leq 10$ months & 3 & $068,95 \%[0.11,1.26]$ & 0.02 & $I^{2}=74 \%, P=0.2$ \\
$\quad>10$ months & 8 & $0.41,95 \%[0.15,0.67]$ & 0.002 & $I^{2}=51 \%, P=0.05$ \\
\hline $\begin{array}{l}\text { Intervention frequencies } \\
\quad\end{array}$ & 4 & & & \\
$\quad$ & & 0.003 & $I^{2}=27 \%, P=0.25$ \\
$\quad>$ days/week & 7 & $0.46,95 \%[0.11,0.81]$ & 0.009 & $I^{2}=80 \%, P<0.002$ \\
\hline
\end{tabular}

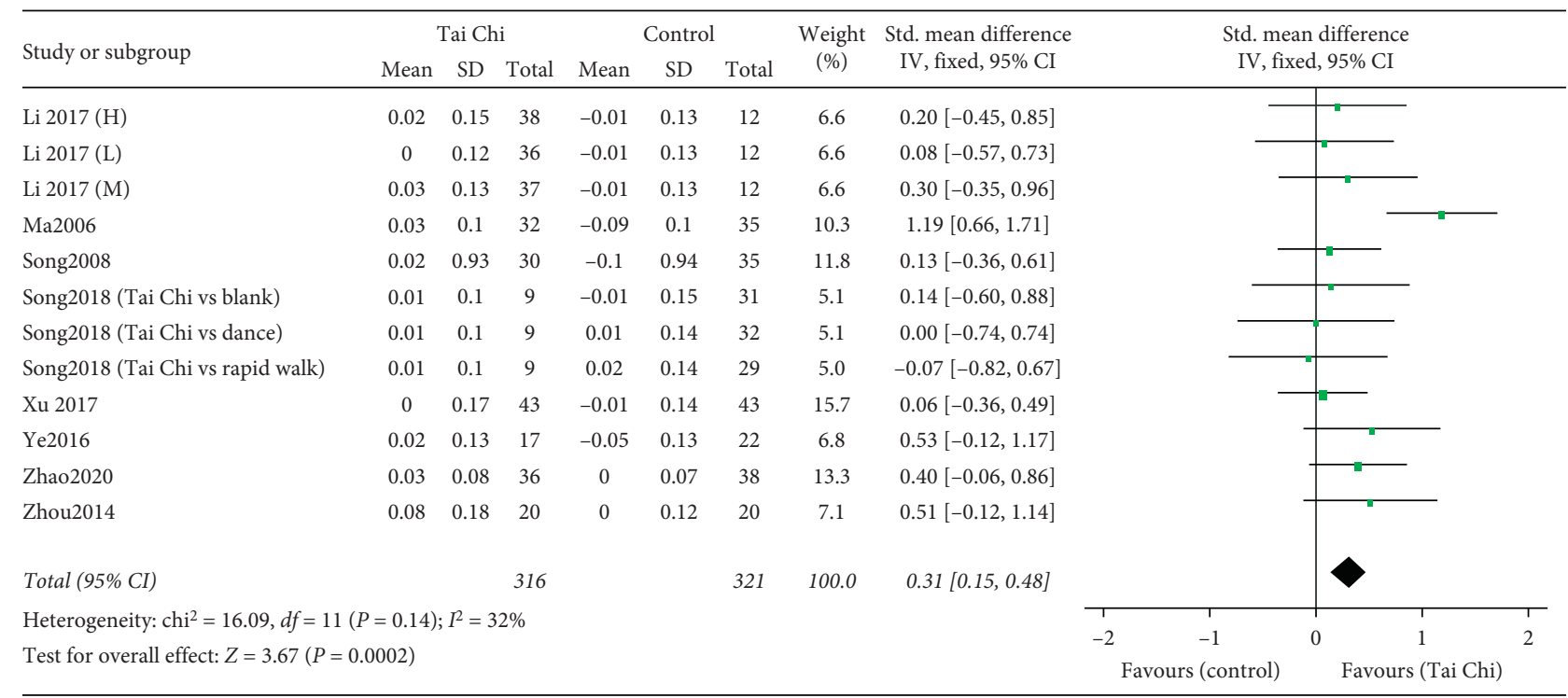

FIgURE 7: Forest plot of the comparison between the Tai Chi and the control group for the outcome BMD change in Ward's triangle.

TABLE 5: Subgroup analyses between the Tai Chi and the nonexercise group for the outcome BMD change in Ward's triangle according to intervention durations and frequencies.

\begin{tabular}{lcccc}
\hline Subgroup & $n$ & SMD, 95\% CI & $P$ & Heterogeneity \\
\hline Intervention duration & & & & \\
$\quad \leq 10$ months & 4 & $0.31,95 \%[0.00,0.61]$ & 0.05 & $I^{2}=0 \%, P=0.66$ \\
$\quad 10$ months & 6 & $0.38,95 \%[0.03,0.73]$ & 0.03 & $I^{2}=60 \%, P=0.03$ \\
\hline $\begin{array}{l}\text { Intervention frequencies } \\
\quad\end{array} \quad$ & & & 0.006 & $I^{2}=0 \%, P=0.87$ \\
$\quad 5$ days/week & 5 & $0.37,95 \%[0.11,0.64]$ & 0.12 & $I^{2}=69 \%, P=0.01$ \\
\hline days/week & 5 & $0.35,95 \%[-0.09,0.79]$ & &
\end{tabular}

results of previous systematic reviews were not uniform, the inclusion of further RCTs can lead to more accurate conclusions; (2) secondly, we added some results, including BMD change in the femoral trochanter and Ward's triangle, to study the effect of Tai Chi on different parts of the body; (3) lastly, we conducted subgroup analyses on control type, intervention duration, and intervention frequency. In this way, the effects caused by different training durations and frequencies were evaluated, and we found that different training durations and frequencies of Tai Chi could result in variable effectiveness.

4.1. Main Results and Analysis. This systematic review and meta-analysis, which was based on 23 RCTs involving 1582 participants, found that Tai Chi may have a positive effect on BMD improvement in the lumbar spine, the femoral neck, the femoral trochanter, and Ward's triangle. Our study showed benefits in improving BMD in the four parts mentioned above in favor of Tai Chi compared with the nonexercise group. However, no significant improvement was found between the Tai Chi and the other exercises group. Besides, different intervention durations and frequencies of Tai Chi may lead to various effects. For BMD in the lumbar spine, only Tai Chi with an intervention frequency of $>4$ days/week was shown to have a beneficial effect, while no significant improvement was found with an intervention frequency of $\leq 4$ days/week. For BMD in the femoral neck, the pooled result showed that significant improvement could only be found in subgroups of an 


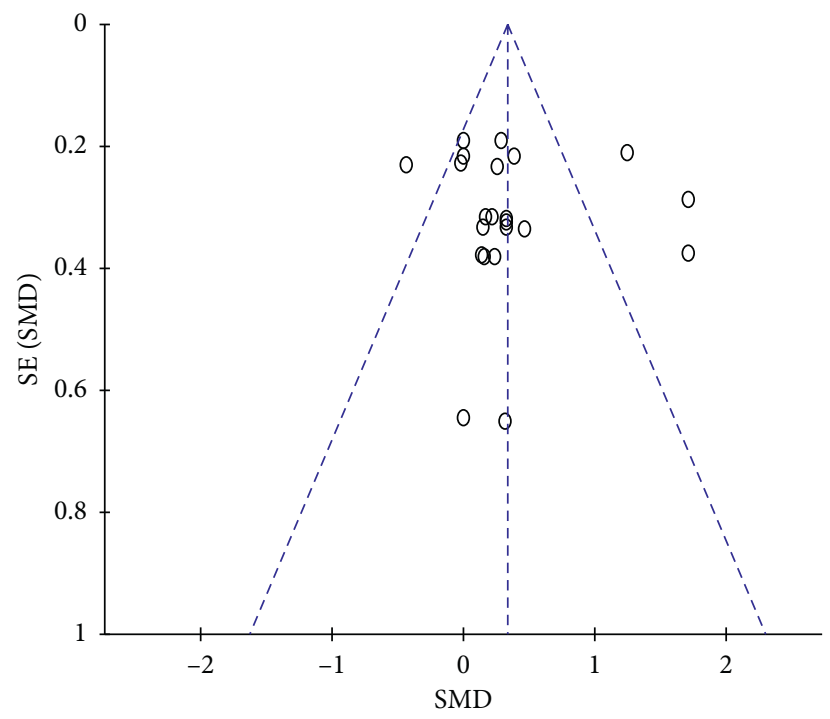

FIGURE 8: Evaluation of publication bias for outcome of BMD change in the lumbar spine (L2-L4).

TABLE 6: Comparisons with other previous meta-analysis.

\begin{tabular}{|c|c|c|c|c|c|}
\hline Author, year & Sun 2016 & Liu 2017 & Zou 2017 & Zhang 2019 & The present meta-analysis \\
\hline $\begin{array}{l}\text { Number of } \\
\text { RCTs }\end{array}$ & 11 & 6 & 20 & 15 & 23 \\
\hline Participants & $\begin{array}{c}\text { Perimenopausal and } \\
\text { postmenopausal } \\
\text { women }\end{array}$ & $\begin{array}{l}\text { Postmenopausal } \\
\text { women }\end{array}$ & $\begin{array}{l}\text { Middle-aged and older } \\
\text { adults }\end{array}$ & $\begin{array}{l}\text { Osteopenia and } \\
\text { primary } \\
\text { osteoporosis }\end{array}$ & $\begin{array}{c}\text { Individual without serious } \\
\text { diseases }\end{array}$ \\
\hline $\begin{array}{l}\text { Search strategy } \\
\text { until (year) }\end{array}$ & 2015 & 2016 & 2016 & 2017 & 20 \\
\hline $\begin{array}{l}\text { Subgroup } \\
\text { analysis }\end{array}$ & Control type & NA & NA & $\begin{array}{l}\text { Control type, } \\
\text { participants }\end{array}$ & $\begin{array}{c}\text { Control type, intervention } \\
\text { duration, and intervention } \\
\text { frequency }\end{array}$ \\
\hline Outcomes & $\begin{array}{l}\text { BMD in the lumbar } \\
\text { spine }\end{array}$ & $\begin{array}{l}\text { BMD in the lumbar } \\
\text { spine and the femoral } \\
\text { neck }\end{array}$ & $\begin{array}{l}\text { BMD in the lumbar } \\
\text { spine, the femoral } \\
\text { neck, and the femoral } \\
\text { trochanter. }\end{array}$ & BMD & $\begin{array}{l}\text { BMD in the lumbar spine, } \\
\text { the femoral neck, the } \\
\text { femoral tochanter, and } \\
\text { Ward's triangle }\end{array}$ \\
\hline
\end{tabular}

intervention frequency of $>4$ days/week and an intervention duration of $>10$ months. For BMD in the femoral trochanter, Tai Chi was shown to have a beneficial effect in all durations ( $\leq 10$ months and $>10$ months) and frequencies ( $\leq 4$ days/ week and $>4$ days/week). For BMD in Ward's triangle, a beneficial effect of Tai Chi was found only after an intervention duration of $>10$ months or a frequency of $\leq 4$ days/ week.

Tai Chi is a moderate-intensity aerobic exercise, characterized by a high demand for neuromuscular coordination, low velocity of muscle contraction, and no jumping. Tai Chi affects bone health through the two following aspects: one is the mechanical regulation system, that is, the beneficial effect on bone comes from the mechanical stress generated during the Tai Chi exercise; the other is the hormone regulation system, and one study found that the serum bone-specific alkaline phosphatase (BAP) concentration and the ratio of BAP to pyridinoline (BAP/PYD) increased significantly after six weeks of Tai Chi exercise, indicating the bone-promoting effect in Tai Chi [39]. In addition, Tai Chi also plays a positive role in psychological adjustment [40]. Although showing no significant BMD improvement compared to other exercises, including resistance exercise, rapid walking, dancing, and rope skipping, Tai Chi is still recommended as a suitable exercise for older patients with rheumatoid arthritis and osteoporotic conditions for smooth, slow, calm, and conscious-based movements, which are barely seen in other strengthening exercises [41]. Till now, some studies have focused on the effectiveness of different training frequencies and durations in Tai Chi. One study has found that Tai Chi was shown to have a significant improvement that is positively related to the intervention duration in functional gait assessed by timed up-and-go tests [42]. Another study has found that a brief high-impact exercise every day is more beneficial to BMD improvement than an exercise of 4 days per week [43]. According to our review, different training durations and frequencies could result in variable effectiveness. However, the interpretation of these results should be treated with caution. In this meta-analysis, high heterogeneity, a 
relatively small number of studies, and generally low quality of included literature raised concerns about the accuracy of the conclusion. A well-designed, large-scale trial is still needed to validate this result.

4.2. Limitations. The overall quality of the included studies was not high. Only 11 RCTs reported appropriate randomization methods [16, 17, 27, 30, 32, 35-37], and 4 RCTs mentioned allocation concealment [16, 26, 37]. Meanwhile, performance bias could not be ruled out because participants cannot be blinded to the Tai Chi exercise. In addition, four trials mentioned blinding of outcome assessment $[16,17,37]$, and 5 RCTs reported a high but nonrandom drop-out rate $[17,27,30]$. At the same time, publication bias also existed. Four RCTs were significantly asymmetrical according to the funnel plot $[25,31,36,37]$. However, differences in the design and methodology of these RCTs cannot be found, which may be caused by the low quality and inadequate information provided in these studies.

The heterogeneity among the studies was significant. Subgroup analyses with respect to control type, intervention duration, and intervention frequency were subsequently carried out, and we found that these three aspects might partly be the source of heterogeneity. However, the above-mentioned three categories can only explain the heterogeneity to some extent and should be interpreted with great caution. There remained substantial unexplained heterogeneity in this review, including study design and study quality. For example, the detailed included participants in each study were slightly different: some were menopausal women, some were elderly women, some were elderly men, and some had hyperlipidemia. Besides, the training style and daily practice time in each study were also different. Various training styles of Tai Chi involving Yang-style, Sun-style, and 24-form were included in this review, and the daily practice time was not the same, ranging from 30 to 90 minutes per day. All these differences may result in high heterogeneity.

The distribution of the included studies is uneven. Most studies were conducted in Asian countries, and only 1 study was from the USA. Therefore, ethnic-based subgroup analysis could not be carried out. Besides, we only performed a search for English and Chinese studies, but other languages should be searched to expand the scope. In the absence of enough data, this study only focused on the efficacy of Tai Chi on BMD improvement, but other aspects, including muscle strength, functional mobility, and fracture incidence, may also be assessed.

4.3. Practical Implications. We synthesized current data of Tai Chi on BMD improvement and found that Tai Chi seemed to be an effective exercise therapy to improve $\mathrm{BMD}$ in the spine, the femoral neck, the femoral trochanter, and Ward's triangle. The current finding, which should be interpreted with caution on account of the low methodological quality and the high heterogeneity, is still a promising reference for future clinical trials. Future studies should focus more on the effectiveness of various training types, frequencies, and durations of Tai Chi, and create a set of standard Tai Chi exercises with specific moves, practice frequency, and training duration for global promotion.

\section{Conclusions}

According to our review, Tai Chi may be effective for BMD improvement and can be promoted as cost-effective exercise therapy. The training time and frequency required for various parts are different. However, due to the limitations of the included studies, large-sample, multi-center, well-designed clinical trials are still required to verify this conclusion. Moreover, future studies should focus more on the relationship between the training time and frequency of Tai Chi and different body parts to create a set of standard Tai Chi exercises with specific moves, practice frequency, and training duration.

\section{Abbreviations \\ BMD: $\quad$ Bone mineral density \\ SR: $\quad$ Systematic review \\ RCT: $\quad$ Randomized controlled trial \\ CENTRAL: Cochrane Central Register of Controlled Trials CBM: Chinese Biomedical Literature Database \\ CNKI: China Knowledge Resource Integrated Database \\ VIP: $\quad$ China science and technology journal database \\ SMD: $\quad$ Standard mean difference \\ CI: $\quad$ Confidence interval.}

\section{Data Availability}

All data generated or analyzed during this study are included within this article.

\section{Disclosure}

Funding bodies played an economic support role in research design.

\section{Conflicts of Interest}

The authors declare that they have no conflicts of interest.

\section{Authors' Contributions}

Y Z, Z-H Z, X-H F, and W-H L contributed to the conception of the study. The manuscript protocol was drafted by $\mathrm{Y} \mathrm{Z}$ and $\mathrm{Z}-\mathrm{H} \mathrm{Z}$ and was revised by $\mathrm{X}-\mathrm{H}$ F and $\mathrm{W}-\mathrm{H}$ L. The search strategy was developed by all the authors and performed by Z-H Z and Y Z, who also independently screened the potential studies, extracted data from the included 
studies, assessed the risk of bias, and completed the data synthesis. Z C arbitrated in cases of disagreement and ensured the absence of errors. All authors have read and approved the manuscript.

\section{Acknowledgments}

This work was funded by the National Key Research and Development Program of China (no. 2017YFC1703304) and the National Natural Science Foundation of China (no. 81873204).

\section{References}

[1] A. Corrado, D. Cici, C. Rotondo, N. Maruotti, and F. P. Cantatore, "Molecular basis of bone aging," International Journal of Molecular Sciences, vol. 21, no. 10, p. 3679, 2020.

[2] P. D. Miller, "Management of severe osteoporosis," Expert Opinion on Pharmacotherapy, vol. 17, no. 4, pp. 473-488, 2016.

[3] D. M. Black and C. J. Rosen, "Postmenopausal osteoporosis," New England Journal of Medicine, vol. 374, no. 3, pp. 254-262, 2016.

[4] K. E. Ensrud and C. J. Crandall, "Osteoporosis," Annals of Internal Medicine, vol. 167, no. 3, pp. ITC17-ITC32, 2017.

[5] H. A. Morris, "Osteoporosis prevention-a worthy and achievable strategy," Nutrients, vol. 2, no. 10, pp. 1073-1074, 2010.

[6] J. M. Lane, L. Russell, and S. N. Khan, "Osteoporosis," Clinical Orthopaedics and Related Research, vol. 372, pp. 139-150, 2000.

[7] M. K. Karlsson and B. E. Rosengren, "Exercise and peak bone mass," Current Osteoporosis Reports, vol. 18, no. 3, pp. 285-290, 2020.

[8] M. G. Benedetti, G. Furlini, A. Zati, and G. Letizia Mauro, "The effectiveness of physical exercise on bone density in osteoporotic patients," BioMed Research International, vol. 2018, Article ID 4840531, 10 pages, 2018.

[9] A. M. Cheung and L. Giangregorio, "Mechanical stimuli and bone health: what is the evidence?" Current Opinion in Rheumatology, vol. 24, no. 5, pp. 561-566, 2012.

[10] K. T. Borer, "Physical activity in the prevention and amelioration of osteoporosis in women," Sports Medicine, vol. 35, no. 9, pp. 779-830, 2005.

[11] M. Tobeiha, M. H. Moghadasian, N. Amin, and S. Jafarnejad, "RANKL/RANK/OPG pathway: a mechanism involved in exercise-induced bone remodeling," BioMed Research International, vol. 2020, Article ID 6910312, 11 pages, 2020.

[12] D. G. Monroe, M. E. McGee-Lawrence, M. J. Oursler, and J. J. Westendorf, "Update on WNT signaling in bone cell biology and bone disease," Gene, vol. 492, no. 1, pp. 1-18, 2012.

[13] K. Ikeda, K. Horie-Inoue, and S. Inoue, "Functions of estrogen and estrogen receptor signaling on skeletal muscle," The Journal of Steroid Biochemistry and Molecular Biology, vol. 191, p. 105375, 2019.

[14] M. J. Devlin, "Estrogen, exercise, and the skeleton," Evolutionary Anthropology: Issues, News, and Reviews, vol. 20, no. 2, pp. 54-61, 2011.

[15] M. S. Lee and E. Ernst, "Systematic reviews of T'ai Chi: an overview," British Journal of Sports Medicine, vol. 46, no. 10, pp. 713-718, 2012.

[16] P. M. Wayne, D. P. Kiel, J. E. Buring et al., "Impact of Tai Chi exercise on multiple fracture-related risk factors in post-menopausal osteopenic women: a pilot pragmatic, randomized trial," BMC Complementary and Alternative Medicine, vol. 12, p. 7, 2012.

[17] R. Song, B. L. Roberts, E.-O. Lee, P. Lam, and S.-C. Bae, “A randomized study of the effects of Tai Chi on muscle strength, bone mineral density, and fear of falling in women with osteoarthritis," The Journal of Alternative and Complementary Medicine, vol. 16, no. 3, pp. 227-233, 2010.

[18] K. Chan, L. Qin, M. Lau et al., "A randomized, prospective study of the effects of Tai Chi Chun exercise on bone mineral density in postmenopausal women," Archives of Physical Medicine and Rehabilitation, vol. 85, no. 5, pp. 717-722, 2004.

[19] L. Qin, S. Au, W. Choy et al., "Regular Tai Chi Chuan exercise may retard bone loss in postmenopausal women: a casecontrol study," Archives of Physical Medicine and Rehabilitation, vol. 83, no. 10, pp. 1355-1359, 2002.

[20] Y. Zhang, Y. Chai, X. Pan, H. Shen, X. Wei, and Y. Xie, "Tai Chi for treating osteopenia and primary osteoporosis: a metaanalysis and trial sequential analysis," Clinical Interventions in Aging, vol. 14, pp. 91-104, 2019.

[21] F. Liu and S. Wang, "Effect of Tai Chi on bone mineral density in postmenopausal women: a systematic review and meta-analysis of randomized control trials," Journal of the Chinese Medical Association, vol. 80, no. 12, pp. 790-795, 2017.

[22] Z. Sun, H. Chen, M. R. Berger, L. Zhang, H. Guo, and Y. Huang, "Effects of Tai Chi exercise on bone health in perimenopausal and postmenopausal women: a systematic review and meta-analysis," Osteoporosis International, vol. 27, no. 10, pp. 2901-2911, 2016.

[23] L. Zou, C. Wang, K. Chen et al., "The effect of Tai Chi practice on attenuating bone mineral density loss: a systematic review and meta-analysis of randomized controlled trials," International Journal of Environmental Research and Public Health, vol. 14, no. 9, p. 1000, 2017.

[24] J. P. T. Higgins and S. Green, Cochrane Handbook for Systematic Reviews of Interventions Version 5.1.0, The Cochrane Collaboration, London, UK, 2011.

[25] Q. W. Bao, C. Gong, X. Z. Shen, and X. Wang, "The preventive effect of Tai Chi on elderly patients with osteoporosis and type 2 diabetes," Chinese Journal of Gerontology, vol. 36, pp. 3246-3248, 2016.

[26] X. Shan and J. W. Kang, "Impacts of Tai Chi as adjuvant therapy on the patients with postmenopausal osteoporosis," Chinese Journal of Modern Nursing, vol. 21, pp. 3729-3731, 2015.

[27] C. Q. Ye, C. W. Wang, G. Y. Wang, C. L. Wang, and B. M. Ji, "The effect of Tai Chi Chuan on middle-aged and elderly women," Chinese Journal of Health Care and Medicine, vol. 18, pp. 494-495, 2016.

[28] X. J. Zhou, C. J. Liu, and J. Li, "Study on the trend of Tai Chi Chuan on bone mineral density in elderly patients with hyperlipidemia," Fujian Sports Science and Technology, vol. 33, pp. 39-42, 2014.

[29] Y. Zhou, "The effect of traditional sports on bone mineral density of menopausal women," Journal of Beijing Sport University, vol. 27, pp. 354-355+60, 2004.

[30] J. L. Song, L. Cheng, and S. W. Chang, "Effects of 48-week Taichi, brisk walking and square dance on bone mineral density in elderly women," Journal of Shandong Sport University, vol. 34, pp. 105-108, 2018.

[31] Y. Song, "Effects of Tai Chi Chuan exercise on bone mineral density and bone metabolism in primary osteoporosis sufferers," Journal of Physical Education, vol. 15, pp. 106-108, 2008. 
[32] F. Xu, "The effect of simplified Tai Chi Chuan on the bone mineral density in postmenopausal women," Journal of Practical Traditional Chinese Medicine, vol. 33, pp. 1428-1429, 2017.

[33] J. Y. Li and L. Cheng, "Effect of different frequency of Taichi exercise on bone mineral density of older women," Chinese Journal of Osteoporosis, vol. 23, pp. 1309-1312, 2017.

[34] H. N. Mao, "Effects of Tai Chi Chuan exercises combined with orally calcium supplement on postmenopausal women's bone mineral density," Chinese Journal of Rehabilitation Medicine, vol. 24, pp. 814-816, 2009.

[35] J. Zhao, "Effects of Tai Chi Chuan on the changes of bone mineral density of perimenopausal women," Chinese Journal of Tissue Engineering Research, vol. 24, pp. 176-180, 2020.

[36] X. W. Ma and W. Z. Wang, "Clinical study on the preventive effect of Tai Chi Chuan on 32 cases of elderly men with bone loss," Shanxi Journal of Traditional Chinese Medicine, vol. 27, pp. 1214-1215, 2006.

[37] J. Woo, A. Hong, E. Lau, and H. Lynn, “A randomised controlled trial of Tai Chi and resistance exercise on bone health, muscle strength and balance in community-living elderly people," Age and Ageing, vol. 36, no. 3, pp. 262-268, 2007.

[38] M. L. Moy, P. M. Wayne, D. Litrownik et al., "Long-term exercise after pulmonary rehabilitation (LEAP): design and rationale of a randomized controlled trial of Tai Chi," Contemporary Clinical Trials, vol. 45, pp. 458-467, 2015.

[39] C.-L. Shen, J. S. Williams, M.-C. Chyu et al., "Comparison of the effects of Tai Chi and resistance training on bone metabolism in the elderly: a feasibility study," The American Journal of Chinese Medicine, vol. 35, no. 3, pp. 369-381, 2007.

[40] J. Li, C. C. Hsu, and C. T. Lin, "Leisure participation behavior and psychological well-being of elderly adults: an empirical study of Tai Chi Chuan in China," International Journal of Environmental Research and Public Health, vol. 16, no. 18, p. 3387, 2019.

[41] D. Cheng, B. Wang, Q. Li, Y. Guo, and L. Wang, "Research on function and mechanism of tai chi on cardiac rehabilitation," Chinese Journal of Integrative Medicine, vol. 26, no. 5, pp. 393-400, 2020.

[42] L. Li and B. Manor, "Long term Tai Chi exercise improves physical performance among people with peripheral neuropathy," The American Journal of Chinese Medicine, vol. 38, no. 3, pp. 449-459, 2010.

[43] C. A. Bailey and K. Brooke-Wavell, "Optimum frequency of exercise for bone health: randomised controlled trial of a high-impact unilateral intervention," Bone, vol. 46, no. 4, pp. 1043-1049, 2010. 